RESEARCH REPORT

\title{
Sex differences in hospital readmission among colorectal cancer patients
}

\author{
Juan Ramon González, Esteve Fernandez, Víctor Moreno, Josepa Ribes, Mercè Peris, Matilde \\ Navarro, Maria Cambray, Josep Maria Borràs
}

J Epidemiol Community Health 2005;59:506-511. doi: 10.1136/jech.2004.028902

See end of article for authors' affiliations

Correspondence to:

Dr E Fernandez, Cancer

Prevention and Control

Unit, Institut Català

d'Oncologia, Avda. Gran

Vía s/n, km 2,7, 08907

L'Hospitalet de Llobregat,

Barcelona, Spain;

efernandez@ico.scs.es

Accepted for publication 28 December 2004

\begin{abstract}
Background: While several studies have analysed sex and socioeconomic differences in cancer incidence and mortality, sex differences in oncological health care have been seldom considered.

Objective: To investigate sex based inequalities in hospital readmission among patients diagnosed with colorectal cancer.

Design: Prospective cohort study.

Setting: Hospital Universitary in L'Hospitalet (Barcelona, Spain).

Participants: Four hundred and three patients diagnosed with colorectal between January 1996 and December 1998 were actively followed up until 2002.

Main outcome measurements and methods: Hospital readmission times related to colorectal cancer after surgical procedure. Cox proportional model with random effect (frailty) was used to estimate hazard rate ratios and $95 \%$ confidence intervals of readmission time for covariates analysed.

Results: Crude hazard rate ratio of hospital readmission in men was 1.61 (95\% $\mathrm{Cl} 1.21$ to 2.15). When other significant determinants of readmission were controlled for (including Dukes's stage, mortality, and Charlson's index) a significant risk of readmission was still present for men (hazard rate ratio: 1.52, 95\% $\mathrm{Cl} 1.17$ to 1.96$)$.

Conclusions: In the case of colorectal cancer, women are less likely than men to be readmitted to the hospital, even after controlling for tumour characteristics, mortality, and comorbidity. New studies should investigate the role of other non-clinical variable such as differences in help seeking behaviours or structural or personal sex bias in the attention given to patients.
\end{abstract}

patients were excluded because they died or were released before they were approached $(\mathrm{n}=74)$, refused to participate in the study $(\mathrm{n}=13)$, had incomplete information or interviews $(n=27)$, or lived at $100 \mathrm{~km}$ or more from the hospital $(n=6)$. No differences between them and the patients included according to age, sex, Dukes's stage, tumour site, and overall survival were seen (data not shown).

The outcome variable in this study is readmission, considering it as a potential recurrent event (colorectal cancer patients may have several readmissions after discharge). The date of surgery was taken as the beginning of the study period. Patients were actively followed up until June 2002. Consequently, the length of follow up can differ for each patient, depending on the surgery date. Some premature censoring might also occur because of death, migration, or change of hospital. The first readmission time has been considered as the time between the date of the surgical procedure and the first readmission to hospital related to colorectal cancer. The following readmission times have been considered as the difference between the last discharge date and the current hospitalisation date. In total, 1125 readmission events were recorded. As comorbidity may influence the likelihood of hospital readmission, ${ }^{16}$ we have only considered readmissions related to colorectal cancer. We obtained this information from the discharge diagnosis registered in the minimum basic dataset maintained by the department of clinical documentation. The following diagnostic codes of the International Classification of Disease, 9th revision clinical modification, were considered: 153-155, 159, 196-199, 202, 211, 230, 235, 280, 281, 284, 287, 288, 453, 513, $522,553,557,558,560,562,565,569,571,789,996-999$; and the procedures: V58, V55, and V71. Hence we excluded 264 re-hospitalisations because the main diagnostic or procedures investigation approved the study and all the patients gave written informed consent to participate. Other 120 (23\%) 
Table 1 Distribution of 403 colorectal cancer patients according to sex and selected variables

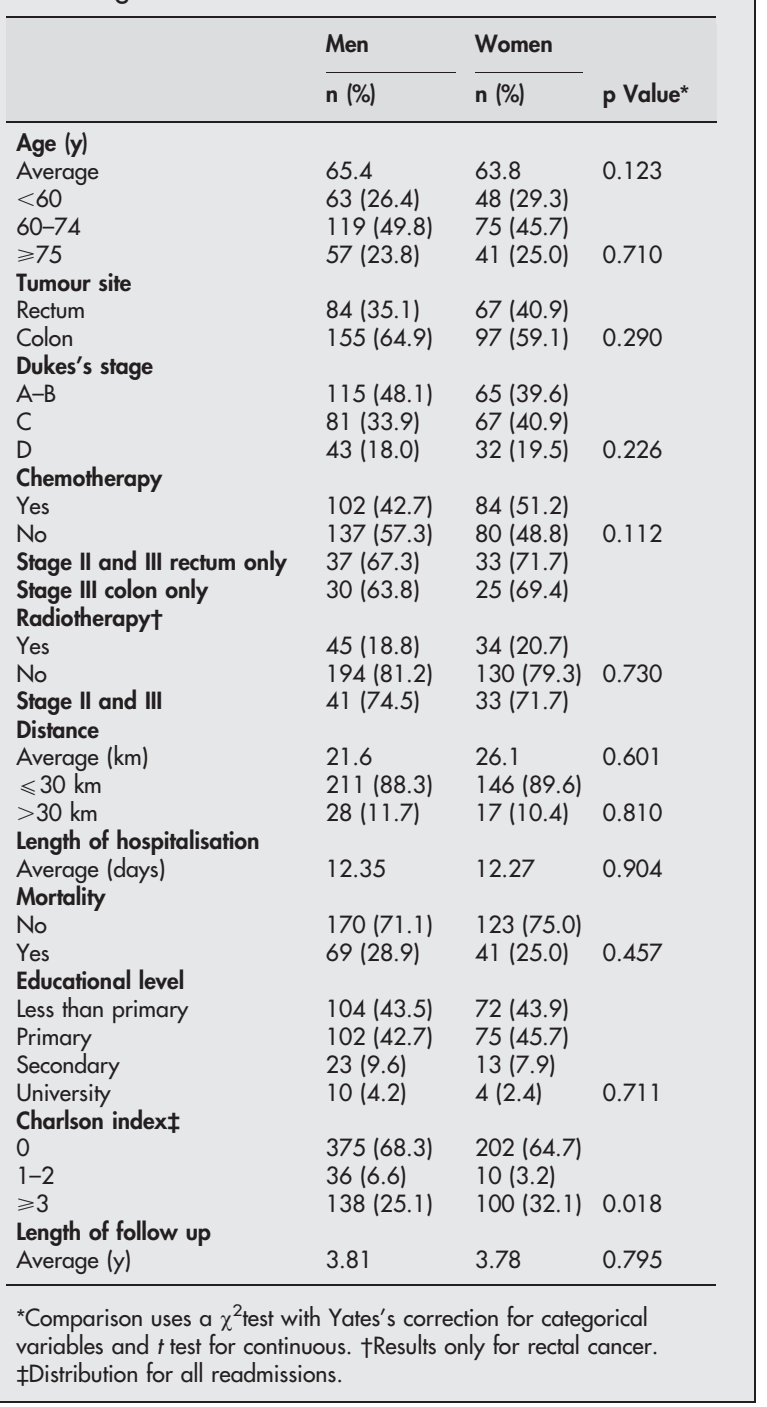

were not related to colorectal cancer. Thus, the final dataset consisted on 861 re-hospitalisations recorded on the 403 patients included in the study.

The main independent variable was sex, and other variables considered as potential confounders were age $(<60,60-74, \geqslant 75$ years), tumour site (rectum, colon), tumour stage (Dukes's classification: $\mathrm{A}-\mathrm{B}, \mathrm{C}$, or D), type of treatment (chemotherapy, radiotherapy), distance from living place to hospital $(\leqslant 30 \mathrm{~km},>30 \mathrm{~km})$, educational level (less than primary, primary, secondary, university). Given that radiotherapy is an exclusive treatment for patients with rectal cancer, to analyse both variables in multivariate models we have created a variable that combines both radiotherapy and tumour site (colon, rectum treated with radiotherapy, and rectum treated without radiotherapy). To adjust the risk of readmissions for comorbidity, we have calculated Charlson's index ${ }^{16}$ modified by Librero et al ${ }^{17}$ that incorporates the information from the ICD-9-CM. In addition, to take into account the differences in survival, we have also incorporated it in the models.

\section{Statistical analysis}

Readmissions have been analysed both in frequency and time elapse between the two of them. As several readmissions can occur for the same patient, these events are potentially correlated and statistical analysis must account for this. We used a graphical method that compares different nonparametric estimators of the distribution function of hospitalisation times ${ }^{18}{ }^{19}$ to confirm the correlation between the times of re-hospitalisation for each patient. ${ }^{19}$ Then hospitalisation times were modelled with a proportional hazard's model that included a random effect (frailty) to account for the within subject correlation between events. ${ }^{20}{ }^{21}$ Hazard rate ratios (HR) and 95\% confidence intervals (CI) of readmission were calculated for each covariate. ${ }^{22}$ Charlson's index was modelled as a time dependent covariate. One and three year probability of readmission and the median time of readmission were calculated by means of a nonparametric estimation under a gamma frailty model. ${ }^{19}$ Yates's corrected $\chi^{2}$ test or $t$ test were used to compare the variable distributions between sexes, as appropriate. The MannWhitney U or Kruskall-Wallis tests were used to compare the number of hospital readmission for the variables studied. All analysis was done using both survival and survrec libraries implemented in $\mathrm{R}$ packages. ${ }^{23}$

\section{RESULTS}

Table 1 shows the patient characteristics by sex. No significant differences between men and women were seen in any of the variables analysed, except Charlson's comorbidity index. Men tended to be older, with less advanced tumour stage, and received less frequently chemotherapy.

Table 2 shows the distribution of hospital readmissions. Most of the patients (70.7\% of men and $82.3 \%$ of women) had none or one readmission and only about $5 \%$ of subjects had more than five readmissions. Male patients had, on average, more readmissions than women did (2.3 compared with 1.9, $p=0.060)$. Readmission tended to be more frequent in patients $<60$ years $(\mathrm{p}=0.072)$ and a higher number of hospitalisations was associated with more advanced tumour stages and treatment with chemotherapy $(p<0.001)$. Patients with rectal cancer receiving radiotherapy have more readmissions $(p=0.022)$. Patients who died during follow up had a greater mean number of readmissions $(p<0.001)$. Figures 1 and 2 show that the estimated probability of readmission is always higher for men than for women independently of Dukes's tumour stage or mortality.

Table 3 shows the analysis of time to readmission for the variables included in the study using a non-parametric estimator that accounts for within patient correlation of readmission. The univariate and multivariate (mutually adjusted) Cox frailty models that provides the hazard risk of readmission for each variable are also shown in this table. The one year probability of rehospitalisation was 0.39 in men and 0.32 in women. Median time between readmissions was almost twofold in women than men. This corresponds to a crude $61 \%$ (95\% CI: $21 \%$ to $115 \%)$ excess risk of rehospitalisation for men (table 3). Advanced tumour stage, chemotherapy, high educational level, mortality, and high comorbidity were also associated with smaller times between readmissions (table 3 ). Furthermore, male sex was still associated with time to rehospitalisation ( $\mathrm{HR}=1.52 ; 95 \% \mathrm{CI}$ : 1.17 to 1.96 ) after allowance for stage, comorbidity, and mortality. No effect modification between sex and the rest of predictors of readmission in the final model was present (data not shown).

\section{DISCUSSION}

This study has assessed the time to readmission to the hospital after the date of surgery. The most intriguing finding seen is the sex difference in frequency and time to readmission. Women had a lower probability of readmission to the hospital, even after controlling for other sociodemographic and disease related variables. Several factors could 
Table 2 Frequency and mean number of hospital readmissions according to selected variables

\begin{tabular}{|c|c|c|c|c|c|c|c|c|}
\hline & \multicolumn{7}{|c|}{ Number of hospital readmission } & \multirow[b]{2}{*}{ p Value ${ }^{*}$} \\
\hline & $0 \mathrm{n}(\%)$ & $1 \mathrm{n}(\%)$ & $2 \mathrm{n}(\%)$ & $3 n(\%)$ & $4 \mathrm{n}(\%)$ & $\geqslant 5 \mathrm{n}(\%)$ & mean & \\
\hline \multicolumn{9}{|l|}{ Sex } \\
\hline Female & $87(53.0)$ & $48(29.3)$ & $11(6.7)$ & $8(4.9)$ & $5(3.0)$ & $5(3.0)$ & 1.9 & \\
\hline Male & $112(46.9)$ & $57(23.8)$ & $34(14.2)$ & $13(5.4)$ & $10(4.2)$ & $13(5.4)$ & 2.3 & 0.060 \\
\hline \multicolumn{9}{|l|}{ Age } \\
\hline$<60$ & $47(42.3)$ & $32(28.8)$ & $11(9.9)$ & $7(6.3)$ & $8(7.2)$ & $6(5.4)$ & 2.4 & \\
\hline $60-74$ & $98(50.5)$ & $44(22.7)$ & $27(13.9)$ & $12(6.2)$ & $7(3.6)$ & $6(3.1)$ & 2.1 & \\
\hline$\geqslant 75$ & $54(55.1)$ & $29(29.6)$ & $7(7.1)$ & $2(2.0)$ & $0(0.0)$ & $6(6.1)$ & 1.8 & 0.072 \\
\hline \multicolumn{9}{|l|}{ Tumour site } \\
\hline Colon & $129(51.2)$ & $66(26.2)$ & $27(10.7)$ & $15(6.0)$ & $7(2.8)$ & $8(3.2)$ & 2.0 & \\
\hline \multirow{2}{*}{\multicolumn{9}{|c|}{ Dukes's stage }} \\
\hline & & & & & & & & \\
\hline$A-B$ & $103(57.2)$ & $43(23.9)$ & $16(8.9)$ & $8(4.4)$ & $7(3.9)$ & $3(1.7)$ & 1.8 & \\
\hline c & $67(45.3)$ & $40(27.0)$ & $20(13.5)$ & $7(4.7)$ & $6(4.1)$ & $8(5.4)$ & 2.2 & \\
\hline D & $29(38.7)$ & $22(29.3)$ & $9(12.0)$ & $6(8.0)$ & $2(2.7)$ & $7(9.3)$ & 2.7 & $<0.001$ \\
\hline \multicolumn{9}{|l|}{ Chemotherapy } \\
\hline No & $125(57.6)$ & $51(23.5)$ & $22(10.1)$ & $7(3.2)$ & $4(1.8)$ & $8(3.7)$ & 1.8 & \\
\hline Yes & $74(39.8)$ & $54(29.0)$ & $23(12.4)$ & $14(7.5)$ & $11(5.9)$ & $10(5.4)$ & 2.5 & $<0.001$ \\
\hline \multicolumn{9}{|l|}{ Radiotherapy† } \\
\hline No & $39(52.7)$ & $19(25.7)$ & $6(8.1)$ & $2(2.7)$ & $2(2.7)$ & $6(8.1)$ & 2.0 & \\
\hline Yes & $31(40.3)$ & $20(26.0)$ & $12(15.6)$ & $4(5.2)$ & $6(7.8)$ & $4(5.2)$ & 2.3 & 0.022 \\
\hline \multicolumn{9}{|l|}{ Distance } \\
\hline$\leqslant 30 \mathrm{~km}$ & $174(48.7)$ & $96(26.9)$ & $43(12.0)$ & $16(4.5)$ & $14(3.9)$ & $14(3.9)$ & 2.1 & \\
\hline$>30 \mathrm{~km}$ & $24(53.3)$ & $9(20.0)$ & $2(4.4)$ & $5(11.1)$ & $1(2.2)$ & $4(8.9)^{\circ}$ & 2.2 & 0.818 \\
\hline \multicolumn{9}{|l|}{ Mortality } \\
\hline No & $162(55.3)$ & $72(24.6)$ & $29(9.9)$ & $11(3.8)$ & $9(3.1)$ & $10(3.4)$ & 1.9 & \\
\hline Yes & $37(33.6)$ & $33(30.0)$ & $16(14.5)$ & $10(9.1)$ & $6(5.5)$ & $8(7.3)$ & 2.8 & $<0.001$ \\
\hline \multicolumn{9}{|l|}{ Educational level } \\
\hline Less than primary & $83(47.2)$ & $49(27.8)$ & $24(13.6)$ & $9(5.1)$ & $6(3.4)$ & $5(2.8)$ & 2.0 & \\
\hline Primary & 91 (51.4) & $45(25.4)$ & $16(9.0)$ & $8(4.5)$ & $7(4.0)$ & $10(5.6)$ & 2.2 & \\
\hline Secondary & $21(58.3)$ & $8(22.2)$ & $2(5.6)$ & $1(2.8)$ & $2(5.6)$ & $2(5.6)$ & 2.0 & \\
\hline University & $4(28.6)$ & $3(21.4)$ & $3(21.4)$ & $3(21.4)$ & $0(0.0)$ & $1(7.1)$ & 3.4 & 0.175 \\
\hline
\end{tabular}

contribute to explain this finding. Firstly, sex differences in adverse effects caused by chemotherapy could influence the likelihood of re-hospitalisation. Women may experience higher toxicity than men to chemotherapy. ${ }^{24}$ However, the logical consequence would have been more, but not less, re-hospitalisations as seen in our study. Other possible explanation for the differences in readmissions could be a differential rate of complications after surgery or radiotherapy. Postoperative mortality has been analysed and no clear sex related pattern emerged. Thus, this does not contribute to readmissions rates among women. Although we have included several relevant variables like stage at diagnosis, type of treatment, tumour site, and comorbidity in the analysis, we cannot exclude the possibility of residual confounding attributable to unknown factors that account for the association observed. In this sense, the random effect model used in the analysis may capture this effect attributable to non-observed covariates besides that it takes into account for correlation within recurrent events.

Although no meaningful significant difference in survival by sex was found (HR of death of $0.83,95 \%$ CI 0.68 to 1.02 ,

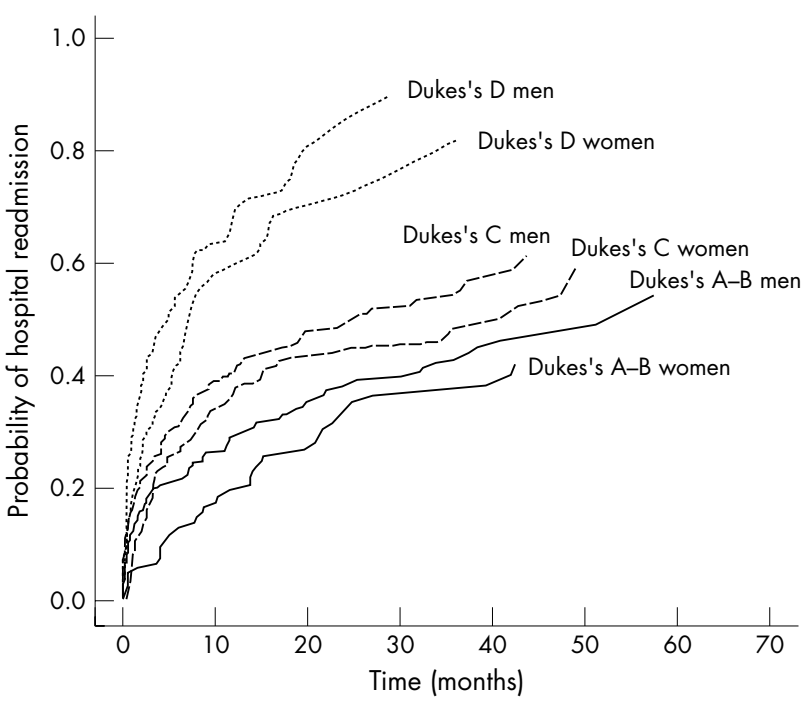

Figure 1 Probability of hospital readmission according to Dukes's stage and sex.

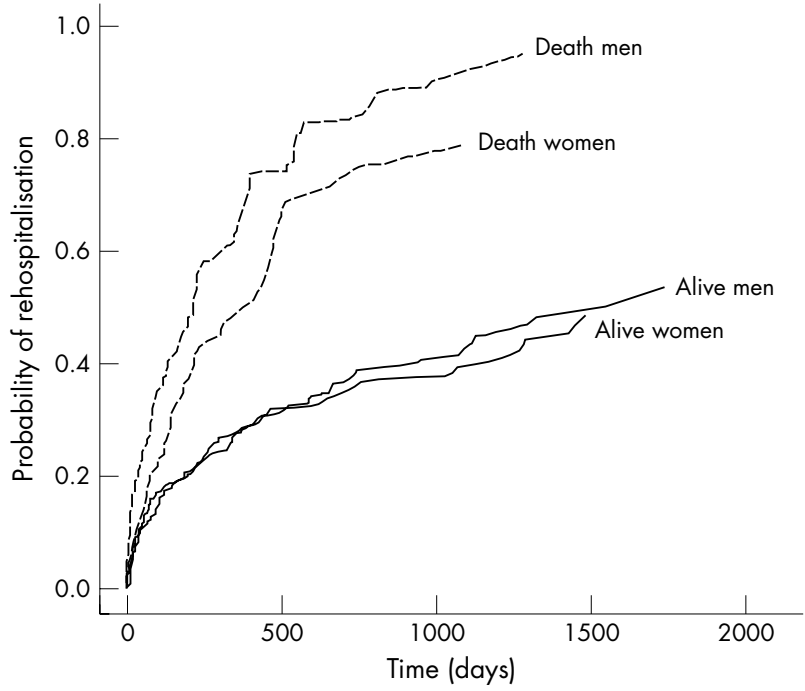

Figure 2 Probability of hospital readmission according to mortality and sex. 
Table 3 Probability, median, and hazard ratios of readmission for selected variables

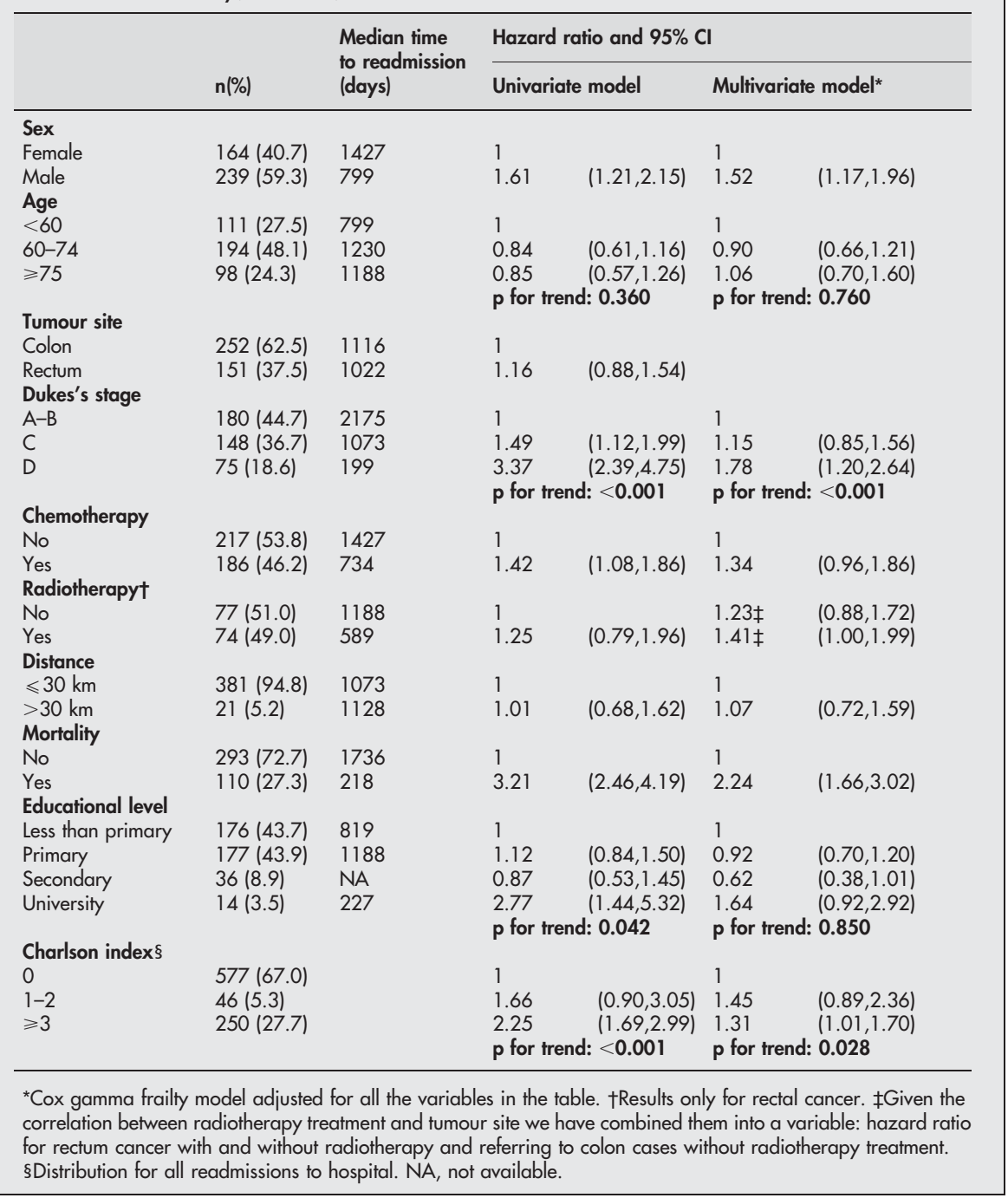

for women compared with men, adjusted for tumour stage, age, tumour site, and surgical procedure), mortality was associated with a higher risk of readmission $(\mathrm{HR}=2.24$, table 3). Factors that could explain the lower probability of readmission in women are beyond the clinical and biological variables studied. Differentials in the social role of women as well as sex based differences in the perception of symptom control could offer alternative explanations..$^{25-27}$ Although it is not possible to explore these alternative pathways with our data, a lower probability of hospital use by women has been reported in this population after excluding pregnancy and delivery related hospitalisations, and adjusting for self perceived health, chronic conditions, and sociodemographic variables. ${ }^{28}$ This finding from a health survey with a sample from the general population is consistent with our finding and points to a more general explanation than medical or demographic factors. ${ }^{26} 27$

Around half of the patients included in this study required a readmission to the hospital with a mean of 2.1 readmissions. Clearly, the main factor associated was stage at diagnosis, as shown in figure 1. Age was inversely related to the probability of readmission, probably because of differences in chemotherapy use according to age, as shown by the absence of differences when other factors are also controlled for in the analysis. Radiotherapy among rectal cancer patients was associated with higher probability of readmission.
In Spain, the universal health coverage warrants the provision of health care to all population and no meaningful inequalities in health care use exist although some inequalities in the access to some specific services (dentists, optometrist) persist..$^{8-10}$ Although distance to hospital has been associated with differences in oncological care, ${ }^{29}{ }^{30}$ in our study this has not been found.

Stage at diagnosis and comorbidity were associated with higher probability of being readmitted to the hospital, which is consistent with their known role in the therapeutic decision procedure and in the prognosis in cancer. Comorbidity was taken into account using Charlson's index, which was included in the model as a time dependent covariable to further adjust for these conditions. Comorbidity has been associated with readmission to hospital ${ }^{16}$ as well as with length of stay ${ }^{31}{ }^{32}$ or complications of treatment. ${ }^{33-35}$ In our study, a higher Charlson's index was seen among women at every admission to the hospital. Charlson's index was associated with a higher probability of readmission but did not modify the risk of readmission of women when it was controlled for. Moreover, it is interesting to note that the use of chemotherapy and radiotherapy in stage III, colon cancer, and in stage II and III, rectal cancer, is similar to that reported in the literature. ${ }^{36}$ As in our case, age and comorbidity were identified as predictor factors of not being offered chemotherapy or radiotherapy. 


\section{What this paper adds}

- Although sex and socioeconomic differences in cancer incidence and mortality have been investigated, sex inequalities in oncological health care use have been scarcely considered. Therefore, we have investigated sex based inequalities in hospital readmission among patients diagnosed with colorectal cancer attending a university hospital.

- The data show that women with colorectal cancer are less likely than men to be readmitted to the hospital, after controlling for well established predictors, such as tumour characteristics and comorbidity. New studies should investigate the role of other non-clinical variables such as differences in help seeking behaviours or structural or personal sex bias in the attention given to patients.

There are some limitations to our study. Firstly, we have analysed readmission to the hospital where all patients were diagnosed and treated. Some patients, especially those not living in the proximity of the hospital may have been admitted to other hospital. With the available data it is not possible to control for this potential source of bias. Moreover, we have analysed separately the readmission from those patients living near $(\leqslant 30 \mathrm{~km})$ and far $(>30 \mathrm{~km})$ from the hospital, and no differences in the mean number of readmissions was present. Furthermore, we excluded from the study those patients living $100 \mathrm{~km}$ or more from the hospital. Admissions to other hospitals would have been a problem only in the case of presenting a differential pattern by sex, which seems unlikely.

On the other hand, we have used strong predictors of readmission and mortality collected in the framework of a case-control study, thus improving their accuracy and validity. Finally, the Cox frailty model used allows us to study a recurrent phenomenon, such as hospital readmission for colorectal cancer, taking into account the potential correlation between the events.

Use of health services in cancer patients has not been a very active area of study in recent years. However, improving monitoring of oncological care use is especially important in the context of a national health service, which is aimed at facilitating an equal use of health services according to the need. ${ }^{38}$ Although countries in Europe perform comparatively well in access to health care and use of health services, ${ }^{39}$ sex inequalities have not disappeared as this study shows.

We conclude that, in the case of colorectal cancer, women are less likely than men to be readmitted to the hospital, even after controlling for tumour characteristics and comorbidity. Thus, new studies should investigate the role of other nonclinical variable such as differences in help seeking behaviours or structural or personal sex bias in the attention given to patients.

\section{ACKNOWLEDGEMENTS}

The authors thank Dr J Marti-Ragué and Dr J R Germà for their help with patient identification and comments on a preliminary version of the manuscript; Dr A Hernández and the department of clinical documentation, Hospital de Bellvitge, for providing the readmission data; and E Guinó for data management.

\section{Authors' affiliations}

J R González, E Fernandez, M Peris, J M Borràs, Cancer Prevention and Control Unit, Institut Català d'Oncologia, Barcelona, Spain

E Fernandez, J M Borràs, Department of Public Health, Universitat de Barcelona, Spain
V Moreno, J Ribes, Epidemiology and Cancer Registry Unit, Institut Català d'Oncologia

M Navarro, Medical Oncology Department, Institut Català d'Oncologia M Cambray, Radiotherapy Oncology Department, Institut Català d'Oncologia

Funding: this study was partially funded by a grant from the Marato of TV3 (contract 48/95), the Spanish Ministry of Health (research grants from the Instituto de Salud Carlos III and Fondo de Investigación Sanitaria: FIS 96/0797, FIS 00/0027, FIS 01/1264, SAF 00/81, RTICC C03/10, and RCESP C03/09).

Conflicts of interest: none declared.

\section{REFERENCES}

1 Fernandez E, Bosetti C, La Vecchia C, et al. Sex differences in colorectal cancer mortality in Europe, 1955-1996. Eur J Cancer Prev 2000;9:99-104.

2 La Vecchia C, Negri E, Levi F, et al. Cancer mortality in Europe: effects of age, cohort of birth and period of death. Eur J Cancer 1998;34:1 18-41.

3 Verbrugge LM. Sex differentials in health. Public Health Rep 1982;97:417-37.

4 Ross CE, Bird CE. Sex stratification and health lifestyle: consequences for men's and women's perceived health. J Health Soc Behav 1994;35:161-78.

5 Macran S, Clarke L, Joshi H. Women's health: dimensions and differentials. Soc Sci Med 1996;42:1203-16.

6 Sayer GP, Britt H. Sex differences in morbidity: a case of discrimination in general practice. Soc Sci Med 1996;42:257-64.

7 Borrell C, Pasarin MI. The study of social inequalities in health in Spain: where are we? J Epidemiol Community Health 1999;53:388-9.

8 Borrell C, Fernandez E, Schiaffino A, et al. Social class inequalities in the use of and access to health services in Catalonia, Spain: what is the influence of supplemental private health insurance? Int J Qual Health Care 2001;13:117-25

9 Regidor E, de Mateo S, Gutiérrez-Fisac JL, et al. Diferencias socioeconómicas en la utilización y accesibilidad de los servicios sanitarios en España. Med Clin (Barc) 1996; 107:285-8.

10 Artazcoz L, Moya C, Vanaclocha $\mathrm{H}$, et al. La salud de las personas adultas. Gac Sanit 2004; 18(suppl 1):56-88.

11 Borras JM, Guillen M, Sanchez V, et al. Educational level, voluntary private health insurance and opportunistic cancer screening among women in Catalonia (Spain). Eur J Cancer Prev 1999;8:427-34.

12 Faggiano $F$, Partanen $T$, Kogevinas $M$, et al. Socioeconomic differences in cancer incidence and mortality. In: Kogevinas $M$, Pearce N, Susser M, et al, eds. Social inequalities and cancer. Lyon: IARC Scientific Publications, 1997:65-206.

13 McMahon LF Jr, Wolfe RA, Huang S, et al. Racial and gender variation in use of diagnostic colonic procedures in the Michigan Medicare population. Med Care 1999;37:712-17.

14 Govindarajan R, Shah RV, Erkman LG, et al. Racial differences in the outcome of patients with colorectal carcinoma. Cancer 2003;97:493-8.

15 Wrigley H, Roderick P, George S, et al. Inequalities in survival from colorectal cancer: a comparison of the impact of deprivation, treatment, and host factors on observed and cause specific survival. J Epidemiol Community Health 2003;57:301-9.

16 Charlson ME, Pompei P, Ales KL, et al. A new method of classifying prognostic comorbidity in longitudinal studies: development and validation. J Chron Dis 1987;40:373-83.

17 Librero J, Peiró S, Ordiñana R. Chronic comorbidity and outcome of hospital care: length of stay, mortality, and readmission at 30 and 365 days. J Clin Epidemiol 1999;52:171-9.

18 Wang MC, Chang SH. Nonparametric estimation of a recurrent survival function. J Am Stat Assoc 1999;94:146-53.

19 Peña EA, Strawderman RL, Hollander M. Nonparametric estimation with recurrent event data. J Am Stat Assoc 2001;96:1299-315.

20 Kelly PJ, Lim LL. Survival analysis for recurrent event data: an application to childhood infectious diseases. Stat Med 2000;19:13-33.

21 Oakes, DA. Frailty models for multiple event times. In: Kein JP, Goel PK, eds. Survival analysis: state of the art. Dordrecht: Kluwer Academic, 1992:371-9.

22 Pickles A, Crouchley R. A comparison of frailty models for multivariate survival data. Stat Med 1995;14:1447-61.

23 The Comprehensive R Archive Network. hitp://cran.r-project.org (accessed 8 Jan 2004).

24 Hodgson DC, Fuchs CS, Ayanian JZ. Impact of patient and provider characteristics on the treatment and outcomes of colorectal cancer. J Natl Cancer Inst 2001;93:501-15.

25 Macintyre S, Hunt K, Sweeting H. Gender differences in health: are things really as simple as they seem? Soc Sci Med 1996;42:617-24.

26 Hibbard JH, Pope CR. Gender roles, illness orientation and use of medical services. Soc Sci Med 1983;17:129-37.

27 Ruiz-Cantero MT, Verdú-Delgado M. Sesgo de género en el esfuerzo terapéutico. Gac Sanit 2004;18(suppl 1):118-25.

28 Fernández E, Schiaffino A, Rajmil L, et al. Gender inequalities in health and health care services use in Catalonia (Spain). J Epidemiol Community Health 1999;53:218-22. 
29 Goodman DC, Fisher E, Stukel TA, et al. The distance to community medical care and the likelihood of hospitalization: is closer always better? Am J Public Health 1997;87:1144-50.

30 Lamont EB, Hayreh D, Pickett KE, et al. Is patient travel distance associated with survival on phase II clinical trials in oncology? J Natl Cancer Inst 2003;95:1370-5.

31 Cleary PD, Greenfield S, Mulley AG, et al. Variations in length of stay and outcomes for six medical and surgical conditions in Massachusetts and California. JAMA 1991;226:73-9.

32 Deyo RA, Cherkin DC, Ciol MA. Adapting a clinical comorbidity index for use with ICD-9-CM adminstrative databases. J Clin Epidemiol 1992;45:613-19.

33 Melfi C, Holleman E, Arthur D, et al. Selecting a patient characteristics index for the prediction of medical outcomes using administrative claims data. J Clin Epidemiol 1995;48:917-26.
34 Brailer DJ, Droch E, Pauly MV et al. Comorbidity-adiusted complications risk. A new outcome quality measure. Med Care 1996;34:490-505.

35 Siegler EL, Stineman MG, Maislin G. Development of complications during rehabilitation. Arch Intern Med 1994;154:2185-90.

36 Ayanian JZ, Zaslavsky AM, Fuchs CS, et al. Use of adjuvant chemotherapy and radiation therapy for colorectal cancer in a population-based cohort. $J$ Clin Oncol 2003;21:1293-300.

37 Scharg D, Gelfand SE, Bach PB, et al. Who gets adjuvant treatment for stage II and III rectal cancer? Insight from surveillance, epidemiology and end results-Medicare. J Clin Oncol 2001;19:3712-18.

38 Hart JT. The inverse care law. Lancet 1971;i:405-12.

39 van Doorslaer $E$, Wagstaff $A$, van der Burg $\mathrm{H}$, et al. Equity in the delivery of health care in Europe and the US. J Health Econ 2000;19:553-83.

\section{THE JECH GALLERY}

\section{Professor Aaron Antonovsky (1923-1994): the father of the salutogenesis}

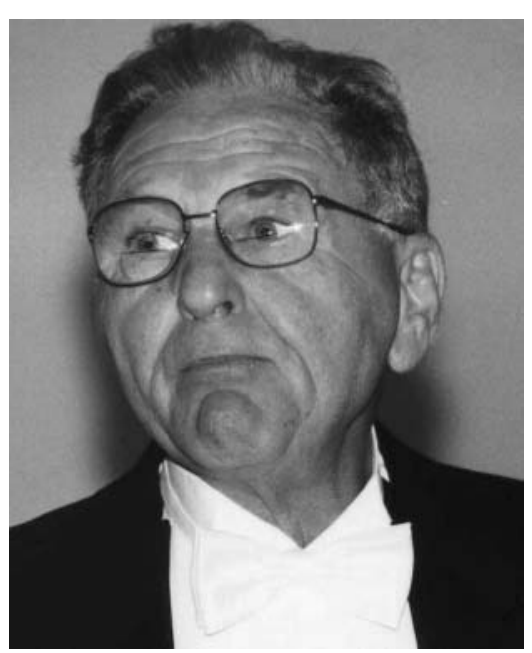

Ten years ago Aaron Antonovsky died after a short period of disease. His death meant a break in the leadership of a new innovative direction in public health research. His fundamental contribution was to raise the philosophical "salutogenic" question of what creates health and search for "the origin of health" rather than to look for the causes of disease. He was born in Brooklyn New York studied sociology and later became professor and head of the department of sociology of health at the faculty of health sciences of the Ben-Gurion University in Israel. Antonovsky had the salutogenic idea while conducting an epidemiological study on problems in the menopause of women in different ethnic groups in Israel. One of these groups shared a common experience-they had survived the concentration camps of the second world war. To his surprise he found that these women had the capability of maintaining good health and lead a good life despite all they had gone through. Antonovsky stated that disease and stress occur everywhere and all the time and it was surprising that organisms were able to survive at all with this constant mass exposure. The question that came to his mind was how we can survive despite all this. In his world health is relative on a continuum and the key research question is what causes health (salutogenesis) not what are the reasons for disease (pathogenesis). The salutogenic perspective focuses on three aspects. Firstly, the focus is on problem solving/finding solutions. Secondly, it identifies generalised resistance resources that help people to move in the direction of positive health. Thirdly, it identifies a global and pervasive sense in individuals, groups, populations, or systems that serves as the overall mechanism or capacity for this process, the sense of coherence (SOC). Today almost 25 years have passed since the question first was raised and it is about time to draw the conclusions of how far research has come. Presently there is a review of this research undertaken at the Nordic school of public health. The preliminary results prove that SOC develops through life time. SOC increases through the life span and it has strong positive correlations to perceived health, mental health, and quality of life. The Institute of Medicine in USA stated in 2003 that one of the most pertinent needs for the education of health professionals for the 21 st century is the necessity of finding a coherent health concept-the salutogenic model would perhaps serve such a purpose.

$\begin{array}{r}\text { Bengt Lindström } \\ \text { The Nordic School of Public Health, Gothenborg, Sweden } \\ \text { Monica Eriksson }\end{array}$
The Salutogenic Project, Nordic School of Public Health

Correspondence to: Dr B Lindström, The Nordic School of Public Health, Box 12133, Nya Varvet, Gothenborg 40242, Sweden; bengt@nhv.se 